\title{
Substance Abuse: From Abstinence to Relapse
}

Saira Javed ${ }^{1}$, Kamran Chughtai ${ }^{2}$, Shoaib Kiani ${ }^{3}$

\section{ABSTRACT}

Objective: The current study objective was to identify and explore the common reasons of relapse after abstinence in drug addiction.

Study Design: Cross sectional.

Place and Duration of Study: The study was conducted at the Department of Psychiatry Combined Military Hospital, Abbottabad from January to August 2019.

Materials and Methods: Individuals who were drug dependent and reported for detoxification were included in the study. Individual interviews were conducted through thematic guide regarding demographic details, name of substance of abuse, duration of substance abuse, number of previous self-attempts to quit the drug, average period of abstinence after self-attempt, reason of relapse after self-attempt, previous assisted attempts to quit the habit, average period of abstinence after assisted attempt, reason of relapse after assisted attempts. The responses were analyzed by using content analysis.

Results: Participants $(\mathrm{N}=34)$ were males, age range 25 to 40 years, $58 \%$ married, $11 \%$ uneducated, $79 \%$ employed, $47 \%$ heroin addiction and $11 \%$ were using cannabis. The common reasons of relapse among self -attempt and assisted-attempt addicts after abstinence in drug addiction were peer pressure (social pressure), negative emotions from family (aggression discouragement and lack of empathy/sympathy), stress (traumatic events, bad physical/mental health)/ lack of motivation and easy availability of drugs (cheap, affordable and distributors are approachable). Resentment against confinement at rehabilitation centers was found only among assisted-attempt addicts after abstinence. Half of the self-attempt participants of the study, were abusing drugs for about last 5 years, $20 \%$ had tried to quit the drug on their own at least twice, $41.18 \%$ for two weeks, $32.35 \%$ for 1 month, and $26.47 \%$ remained abstinent after self-attempt to quit the drug for more than 6 months. On the contrary, $47 \%$ of these individuals had two previous assisted attempts at rehabilitation centers to quit the drug. After assisted attempts $32.35 \%$ remained abstinent for less than one day, $52.94 \%$ for one day, and $14.71 \%$ for less than one week.

Conclusion: It is concluded that the main reasons of relapse are emotional instability, lack of family cooperation and confinement at rehabilitation centers against the will of individual for longer time. Therefore, rehabilitation process should be initiated with the motivation of the individual, followed by psycho education of the family and avoidance of unnecessary prolongs admission without consent of the individual.

Key Words: Abstinence, Rehabilitation, Substance Abuse.

How to cite this: Javed S, Chughtai K, Kiani S. Substance Abuse: From Abstinence to Relapse. Life and Science. 2020; 1(2): 68-71. doi: http://doi.org/10.37185/LnS.1.1.94

\author{
${ }^{1}$ Department of Social and Behavioral Sciences \\ National University of Medical Sciences, Rawalpindi \\ ${ }^{2}$ Department of Psychiatry \\ Combined Military Hospital, Abbottabad \\ ${ }^{3}$ Personal Administration Directorate \\ GHQ, Rawalpindi \\ Correspondence: \\ Ms. Saira Javed \\ Department of Social and Behavioral Sciences \\ National University of Medical Sciences, Rawalpindi \\ E-mail: saira.javedbhati@gmail.com \\ Funding Source: NIL; Conflict of Interest: NIL \\ Received: Jan 16, 2020; Revised: Feb 25, 2020 \\ Accepted: Mar 05, 2020
}

68

\section{Introduction}

Pakistan is one of the highest-ranking countries in the world with maximum number of drug addicts i.e., 6.7 million drug users. Substance abuse is conceptualized as one of the chronic ailments, accompanied with many physical and psychiatric issues that also poses substantial economic burden, not solely for an individual itself but for rest of family members and society too. ${ }^{1}$ In every culture or nation, prevention of relapse is one the biggest and most important challenge. ${ }^{2}$ The phenomenon of relapse is not easy to understand. It is complex, unpredictable 
and dynamic. Many studies have found relapse after successful detoxification and rehabilitation. The core feature of addiction is relapse to drug usage. ${ }^{3,4}$ However, in ideal situation, substance dependency is thought to condense after efficacious detoxification and rehabilitation determinations, but evidence has shown the hardest job for drug addicts is to keep away from drugs. Most of the relapsed cases (90\%) had been reported in time duration of six months, after been discharged from rehabilitation center. With most of the addicts were heroine abuser. ${ }^{4}$ Many national and international programs are being run by various rehabilitation centers in Pakistan. Evidences have shown that $70 \%$ to $90 \%$ substance abusers return to the practice within one year after detoxification from hospitals or rehabilitation centers, if they are constrained and apprehended at the recovery centers. ${ }^{4,5}$ Relapse is a complex phenomenon which resulted in clusters of factors like personality types, temperaments, lack of coping skills, emotional instability, pessimistic approach, traumatic events, aggression, peer pressure, financial constraints, defective family communication, culture and other environmental factors. ${ }^{5,6,7}$ The aim of this study is to explore the reasons for relapse after successful abstinence, and to provide empirical insight for health care professionals. $^{7-8}$

\section{Materials and Methods}

The study was conducted at the Department of Psychiatry from Combined Military Hospital, Abbottabad, from January to August 2019. Questionnaire was designed after extensive literature review of reasons of relapse after abstinence. In depth psychiatric inquiry was also done after filling of structured demographic sheet (tendencies for relapse, interpersonal conflicts, social pressures, self-efficacy, social /family support and employer attitude towards drug abuse) from the participants. Only those individuals were included in this study who were able to sign the consent form.

\section{Results}

In this study thirty four patients were included who were relapsed addicts undergoing treatment at rehabilitation centers. All participants were males, mostly 25 to 40 years of age, $58 \%$ were married, $11 \%$ were uneducated, $79 \%$ were employed. Most common drug of abuse was heroin and cannabis about $47 \%$ and $32 \%$ respectively in addition with other drugs like ice, cough syrups and barbiturates. In this study it is evident to mention that $14.7 \%$ participants have shown no specific evidence of relapse after self and assisted attempt. Reason of relapse after self-attempt were recorded $26.5 \%$ due to peer pressure (social pressure), $41.2 \%$ have reported that negative emotions from family (aggression discouragement and lack of empathy/sympathy) resulted in relapse. Furthermore, $14.7 \%$ participants reported stress (traumatic events, bad physical/mental health) and $2.9 \%$ easy availability of drugs (cheap, affordable and distributors are approachable) were main cause of relapse after- self attempt of abstinent. In contrast, reason of failure after assisted attempt or relapse in $20.6 \%$ were because of peer pressure (social pressure), negative emotions from family (aggression discouragement and lack of empathy/sympathy) were the cause in $5.9 \%$ only drug addicts, whereas lack of motivation was in $2.9 \%$ and $55.9 \%$ was resentment against confinement at rehabilitation centers as shown in table 1.

\begin{tabular}{|c|c|c|c|c|c|}
\hline \multicolumn{3}{|c|}{$\begin{array}{l}\text { Reason for relapse after self- } \\
\text { attempt }\end{array}$} & \multicolumn{3}{|c|}{$\begin{array}{l}\text { Reason for relapse after } \\
\text { assisted attempt }\end{array}$} \\
\hline Themes & $\mathbf{N}$ & (\%) & Themes & $\mathbf{N}$ & (\%) \\
\hline $\begin{array}{l}\text { Peer Pressure } \\
\text { (Social Pressure) }\end{array}$ & 9 & 26.5 & $\begin{array}{l}\text { Peer } \\
\text { Pressure } \\
\text { (Social } \\
\text { Pressure) }\end{array}$ & 7 & 20.6 \\
\hline $\begin{array}{l}\text { Negative } \\
\text { Emotions from } \\
\text { Family } \\
\text { (aggression } \\
\text { discouragement } \\
\text { and lack of } \\
\text { empathy/sympathy) }\end{array}$ & 14 & 41.2 & $\begin{array}{l}\text { Negative } \\
\text { Emotions } \\
\text { from Family } \\
\text { (aggression } \\
\text { discouragement } \\
\text { and lack of } \\
\text { empathy/ } \\
\text { sympathy) }\end{array}$ & 2 & 5.9 \\
\hline $\begin{array}{l}\text { Stress } \\
\text { (traumatic } \\
\text { events, bad } \\
\text { physical/mental } \\
\text { health) }\end{array}$ & 5 & 14.7 & $\begin{array}{l}\text { Lack of } \\
\text { Motivation }\end{array}$ & 1 & 2.9 \\
\hline $\begin{array}{l}\text { Easy availability } \\
\text { of drugs } \\
\text { (cheap, } \\
\text { affordable and } \\
\text { distributors are } \\
\text { approachable) }\end{array}$ & 1 & 2.9 & $\begin{array}{l}\text { Resentment } \\
\text { against } \\
\text { Confinement }\end{array}$ & 19 & 55.9 \\
\hline
\end{tabular}

In self-attempt, $50 \%$ of participants were abusing drugs for about last 5 years. $20 \%$ of these individuals 
had tried to quit the drug on their own (selfattempted) at least twice in last five years, $41.18 \%$ for two weeks, $32.35 \%$ for 1 month, and $26.47 \%$ remained abstinent after self-attempt to quit the drug for more than 6 months. On the contrary, $47 \%$ of these individuals had two previous assisted attempts at rehabilitation centers to quit the drug. After assisted attempts $32.35 \%$ remained abstinent for less than one day, $52.94 \%$ for 1 day, and $14.71 \%$ for less than 1 week as shown in table 2 .

Table 2: Frequency of duration of abstinent in self and assisted abstinence

\begin{tabular}{lcccc}
\hline $\begin{array}{l}\text { Duration } \\
\text { Abstinent }\end{array}$ & \multicolumn{2}{c}{$\begin{array}{c}\text { Self- } \\
\text { Attempt }\end{array}$} & \multicolumn{2}{c}{$\begin{array}{c}\text { Assisted } \\
\text { Attempt }\end{array}$} \\
& N & $\mathbf{( \% )}$ & N & (\%) \\
Less Than 1 Day & - & - & 11 & $32.35 \%$ \\
1 Day & - & - & 18 & $52.94 \%$ \\
Less Than 1 & - & - & 5 & $14.71 \%$ \\
Week & & & & \\
2 Weeks & 14 & $41.18 \%$ & - & - \\
1 Months & 11 & $32.35 \%$ & - & - \\
6 Months or & 9 & $26.47 \%$ & - & - \\
more & & & & \\
\hline
\end{tabular}

\section{Discussion}

The most common challenge faced by community, family or by drug abuse individual himself is of relapse. Relapse is accompanied by many psychosocial factors that lead to abstinent. ${ }^{9,10}$ The study explored the common reasons for the relapse of substance abuse. Evidences have shown that the excessive abuse of heroine drug is followed by cannabis. Interestingly, many drug addicts reported that they intent to stop the habit of substance abuse, $72 \%$ participants tried to quit the habit of drug abuse willingly by noticing its consequences in daily life and on their health, but they also reported that despite the factor of motivation and insight of consequences they were unable to quit and were not able to continue abstinence. The empirical evidence of the current study is opposing to the previous studies where researchers found it was difficult for the abusers to quit drugs. ${ }^{8,11}$

It has been seen that substance abusers who were self-motivated were able to retain their abstinence for an extended period of six months. Conversely, those participants who were forced to leave the habit against their will in rehabilitation centers, the abstinence time is less than one week and only few 70 were able to maintain abstinence for six months or more There are numerous factors responsible for drug abuser relapse. ${ }^{8}$ Identification of causes among addicts associated with relapse can help to devise a management plan so that patients can continue abstinent effectively. ${ }^{9}$ Studies have explained that relapse is more expected to happen among individuals who have maladaptive coping strategies ${ }^{8}$, low socioeconomic status ${ }^{10}$, higher distress ${ }^{11,13}$ and anxiety. ${ }^{12,13}$ Similar trends have been seen in this study, where highest relapse rate has been found among individual with negative emotions and receive insufficient support from their loved ones. ${ }^{14,15}$ Respondents $41 \%$ have reported that negative emotions from the family demotivates them. Furthermore, $26 \%$ individuals explained that peer pressure leads to relapse in otherwise motivated individuals.

It is important to document that duration of abstinence was higher among those participants who were convinced and encouraged to quit habit as compared to those participants who were forced to choose abstinent against their choice. ${ }^{16,17}$ Apart from many other bio-psycho-social causes that eventually contribute to relapse, social/peer pressure and negative emotions from family are the most dominant. Positive support from family members induce confidence, brings emotional stability and develop optimistic approach in addicts that motivates them to quit drug abuse by bringing positive reinforcement. It is important to motivate the drug abuser to quit but equally important is to educate member to identify negative behaviors and approaches so that rehabilitation and abstinence of the individual is more operative, efficient and persistent. ${ }^{17,18,19}$

\section{Conclusion}

It is concluded that efficient rehabilitation programs are required to avoid relapse after abstinence as number of successful cases are lower than the expected rate. It is also important to bring insight among drug abusers through various formal and non-formal education programs. Individuals must not be confined to rehab against their consent. The family needs to be educated about consequences of issue. Finding a tailor-made solution for these individuals may substantiate to be like exploring a needle in haystack, but it's worth trying to facilitate 
these individuals who have been casted out of the society.

\section{REFERENCES}

1. Aziz K, Mohsen N, Jafar H, Rostam M. Survival Analysis of Drug Abuse Relapse in Addiction Treatment Centers. Int J High Risk Behav Addict. 2015; 4: e23402.

2. Venniro M, Caprioli D, Shaham Y. Novel models of drug relapse and craving after voluntary abstinence. Neuropsychopharmacology. 2019; 44: 234-5.

3. Korlakunta A, Chary RSS, Reddy CMP. Reasons for relapse in patients with alcohol dependence. AP J Psychol Med. 2012; 13:108-4.

4. Appiah R, Danquah SA, Nyarko K, Ofori-Atta AL, Aziato L. Precipitants of substance abuse relapse in Ghana: $A$ qualitative exploration. Journal of drug issues. 2017; 47: 104-15.

5. McCabe SE, Cranford JA, Boyd CJ. Stressful Events and Other Predictors of Remission from Drug Dependence in the United States: Longitudinal Results from a National Survey. J Subst Abuse Treat. 2016; 71: 41-7.

6. Atadokht A, Hajloo N, Karimi M, Narimani M. The role of family expressed emotion and perceived social support in predicting addiction relapse. Int J High Risk Behav Addict. 2015; 4: e21250.

7. Appiah R, Boakye KE, Ndaa P, Aziato L. "Tougher than ever": An exploration of relapse prevention strategies among patients recovering from poly-substance use disorders in Ghana. Drugs: Education, Prevention and Policy. 2018; 25: 467-74.

8. kocak ND, Eren A, Akturk UA, Arinc S, Senqul A. Relapse rate and factors related to relapse in a 1 years follow up of subjects participating in smoking cessation program. Respir Care. 2015; 60: 1796-803.

9. Matto SK, Chakrabarti S, Anjaiah M. Psychosocial factors associated with relapse in men with alcohol or opioid dependence. Indian J Med Res. 2009; 130: 702-8.

10. Chalana H, Kundal T, Gupta V, Malhari AS. Predictors of relapse after inpatient opioid detoxification during 1 year follow up. J Addict. 2016: 7620860.

11. Dixit S, Chauhan VS, Azad S. Social support and treatment outcome in Alcohol dependence syndrome in Armed forces. J clin Dign Res. 2015; 9: VC01-VC05.

12. Bold KW, McCarthy DE, Minami H, Yeh VM, Chapman GB, Waters AJ. Independent and interactive effects of real time risk factors on later temptations and lapses among smokers trying to quit. Drug alcohol Depend. 2016; 158: 30-7.

13. Al Abeiat DD, Hamdan-mansour AM, Hanouneh SI, Ghannam BM. Psychosocial predictors of relapse among patients with alcohol problem. Curr Drug Abuse Rev. 2016; 9: 19-25.

14. Macey PR. Alcohol Use Disorder Recovery and Relationships: The Impact of Family Functioning on the PreFrontal Cortex and Romantic Relationships of Individuals in Recovery from Alcohol Use Disorder (Doctoral dissertation) 2019.

15. Naji L, Dennis BB, Bawor M, Plater C, Pare G, Worster A, et al. A Prospective Study to Investigate Predictors of Relapse among Patients with Opioid Use Disorder Treated with Methadone. Subst Abuse. 2016; 10: 9-18.

16. Adinoff B, Carmody TJ, Walker R, Donovan DM, Brigham GS, Winhusen TM. Decision-making processes as predictors of relapse and subsequent use in stimulant-dependent patients. Am J Drug Alcohol Abuse. 2016; 42: 88-97.

17. Yang M, Mamy J, Gao P, Xiao S. From abstinence to relapse: a preliminary qualitative study of drug users in a compulsory drug rehabilitation center in Changsha, China. PLoS One. 2015; 10: e0130711.

18. Albuquerque RC, Nappo SA. Reasons to crack consumption relapse. Users' perspective. Jornal Brasileiro de Psiquiatria. 2018; 67: 194-200.

19. Chan GH, Lo TW, Tam CH, Lee GK. Intrinsic motivation and psychological connectedness to drug abuse and rehabilitation: The perspective of self-determination. International journal of environmental research and public health. 2019; 16: 1934. 